\title{
Analyzing Effects of Various Kinds of Multi-Wall Carbo Nanotubes (MWCNT) on Performance of Water Base Mud (WBM)
}

\author{
Koorosh Tookallo* \\ Department of Petroleum Engineering, Islamic Azad University-Central Tehran Branch, Iran \\ *Corresponding author: Koorosh Tookallo, Department of Petroleum Engineering, Islamic Azad University-Central Tehran Branch, Tehran, Iran
}

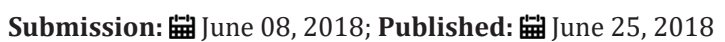

\begin{abstract}
Due to the significance and unique properties of Multi-Wall Carbon Nanotubes (MWCNT), in the present investigation, the viability of these materials in the Water-Based Mud (WBM) is assessed. The impacts of various kinds of MWCNT, mud additives and surfactants on the rheological properties, water loss and drilling fluid stability of the WBM are experimentally investigated. The results have demonstrated various kinds of MWCNT, additives, and surfactants have affected the rheological properties of the WBM. Adding MWCNT and Polyethylene Glycol (PEG) alone or together decrease the terms of rheological properties performance as subsequent order CNT; CNT + PEG; PEG. Surface modified carbon nanotube (Functionalize Carbon Nano Tube [FCNT]) improves rheological properties of the WBM and increases the shale recovery. All in all, the presence of Multi-Wall Carbon Nanotubes increases the efficiency of polymers and improves the rheological properties and performance of the water base mud.
\end{abstract}

Keywords: Water base mud (WBM); Drilling mud; Shale stability; Nanoparticles; Multi-Wall Carbon Nanotubes; Rheological properties

Abbreviations: MWCNT: Multi-Wall Carbon Nanotubes; WBM: Water-Based Mud; PEG: Polyethylene Glycol; FCNT: Functionalize Carbon Nano Tube; OBM: Oil Base Muds; WBM : Water-Based Mud; PHPA: Partially Hydrolyzed Polyacrylamide; RIPI: Research Institute of Petroleum Industry of Iran; MT: Mixing Time; API: American Petroleum Institute

\section{Introduction}

Nowadays, the maintenance of wellbore stability is a very important aspect of drilling. Water invasion to the shale formations is resulted due to weakening the wellbore and it causes many problems, e.g. like stuck pipe and hole-collapse [1]. The problem of wellbore instability in the shale formation is well-known in the drilling industry since over $75 \%$ of the drilled formations consist of shale rocks. Any problematic shale is a serious technical problem, which causes $90 \%$ of wellbore instability problems, time spending, and revenue in the petroleum explorations [2].

Due to the characteristic of Water sensitivity of the shale in relation to its ionic composition and clay content, the formation is seen as the most troublesome issue for the drillers. Shales are also troublesome since they have a very low Nano-Darcy permeability with very small nanometer-sized pore throats that are not effectively sealed by the solids in conventional drilling fluids. The unstable tendency of the water sensitive shale maybe related to water adsorption and clay hydration [3].

In the past, the balanced activity Oil Base Muds (OBM) were used for drilling through troublesome shale formations [4]. OBM subject to its superior shale stabilization characteristic can solve such problems of wellbore instability [5]. OBM is a key solution for maintaining the stability of the shale [6]. However, the use of OBM is limited largely due to its environmental restriction (particularly in offshore drilling), costliness and safety [7].

Therefore, design and development of Water-Based Mud (WBM) with OBM performance is currently seen as an area of great interest in the oil industry.

WBM, which is consisting of potassium chloride ( $\mathrm{KCl})$ and polymer, was introduced in the 1960s. Partially Hydrolyzed Polyacrylamide (PHPA) provides coatings and aids to stabilize the shale by polymer protective layer [6]. Van Oort by replacing OBM with WBM in some Algerian fields, proving that the application of specific additives, i.e. $\mathrm{KCl}$ and polymer improve shale stability [8]. In other areas, where the inhibition to restrain the chemical alteration of the shale is required, potassium-base muds may be used. Potassium ions exchange with sodium or calcium ions on the interlayered clays and smectites [5].

Chemicals cannot perform their desired function effectively in the drilling mud system. Therefore, in order to reach the desired viscous and gelling properties under high pressure and 
high temperature, the drilling mud must comprise of the specific components, e.g. Nanoparticles, which have stability under extreme conditions. The excellent thermal conductivity of Nanobase fluids associated with temperature and pressure tolerances, it can be a better choice. Nanoparticles have the potential to become a permanent constituent of all drilling mud systems, as they can be an efficient solution of many down-hole problems. NPs as a great alternative replace the traditional strategies and allow current drilling industry to go beyond the limits in order to reach those particular hydrocarbons regularly known as inaccessible [9].

WBM is rather more in contact with the clay than OBM. This contact may cause instability. In order to reduce the invasion of drilling fluids, the drilling fluids should form internal or external mud cake [10]. Normal additives cannot form good mud cake, because of small-size pore throat and low shale permeability. Pore throat plugging may not be achieved in the shale, because of the large size of regularly used solid mud additives, which do not plug pore throat. Normal solid particles are approximately 100 times larger than pore throats [11].

The slow flux of filtrate of WBM into the formation leads to a significant pore pressure zone near the wellbore wall and subsequently wellbore instability. Therefore, physical plugging of Nanoscale pore throats can be implemented to reach the several benefits, including pore pressure reduction owing to its feature of preventing the mud filtrate influx toward the shale, while the shale swelling is reduced owing to its feature of avoiding the more interaction between the shale and mud filtrate, the high membrane efficiency is generated due to the shale permeability reduction and consequently the shale stability [8]. The experiments have shown that NPs improve the rheological properties of Nanofluids [12].

Recently, Nanobase drilling fluids have been formulated and resulted in the improvement of rheological properties, i.e. the stability and the gelling property, and the ultrathin mud cake. Nanobase fluids reduce any formation damages by the elimination of spurt loss. Ultrathin mud cake dramatically decreases the differential pipe sticking, and as a result, Nanobase fluid is applied in the formation with the high permeability [13].

Due to the following facts, the Nano (Nanos) additives have the potential to be used in drilling operations; firstly, the huge surface area of NPs increases the interactions between Nanos and reactive shale and resolve borehole problems. Secondly, the less kinetic energy of NPs reduces the abrasive effect of Nanos on downhole equipment, which leads to damage. In conclusion, Nanos are very effective at low concentrations, as it is an advantage for the ecosystem and industry [14]. An alternate approach for shale stability base on the research works of Sensory, Chenevert, and Sharma conducted on Nano-silica (nS), it is shown that the flow of fluids through an Atoka shale plug could be shut off by NPs. In fact, what they essentially conducted was plugging the nano-sized pores in the shale by using the nano-silica particles [10]. Previously, the test results on the gas shale samples shown that formulating the mud properly and choosing appropriate nano materials with proper size and concentration are the keys to prevent water flow into the shale samples with a wide range of initial permeability from in the range of 1 to 100.000 Nano-Darcy (nD) [14]]"

Adding the functionalized Multi-Wall Carbon Nanotube (MWCNT) increases the yield point and plastic viscosity of WBM, reduces spurt lost, creates uniform mud cake, the pipe sticking risk is reduced and torque decreases during drilling operations drag. By Using MWCNT's enhance the annular viscosity, therefore holecleaning and lifting capacity compare with conventional WBM is improved [15]. MWCNT under high temperature and pressure wells can be replaced by the conventional viscosity agents, e.g. organic polymers, clay or fatty acids. The application of MWCNT with the specific trace amounts, preferably less than $3 \%$ by weight, would not cause additional problems, so the mud can pump better [16].

Drilling fluid containing graphene-based materials reduces the shale permeability, closing its pores and achieving better results than the conventional polymers, particularly at high temperatures [17]. MWCNT with the shield agent (PHPA and PAC) allows us to use fewer NPs, which produces no spurt during API filtration test [3]. MWCNT improves the rheological properties, increases thermal conductivity and shear stress, while water loss is reduced [18], the corrosion resistance is improved, and viscosity is improved, as the electrical conductivity, wettability alteration, and the sustainability of the shale are improved. Quintero et al. found that concentrations of NPs for the shale stability should be in the range from 5 to $150,000 \mathrm{ppm}$. They found that NPs with the surface charge such as MWCNT could help to shale stability. The small size of NPs allows good access to the shale matrix [19]. Amanullah et al. [3] found that MWCNTs may increase the viscosity of WBM fluid composition by at least 10 centipoises (cp), providing additional gelling capacity, whereas the water loss and thickness of mud cake are reduced [20].

According to my previous research, by adding MWCNT and PEG alone or together have different effects on the rheological properties of WBM. The addition of MWCNT alone almost improves the rheological properties of WBM, while the addition of PEG alone reduces the rheological properties of the base mud. Furthermore, the addition of PEG to the sample consisting of MWCNT reduces the viscosity and the yield point of WBM. In addition, the viscosity and the yield point of those samples containing MWCNT and PEG are higher than those samples consisting of PEG alone. By increasing the size (diameter and length) of MWCNT, the viscosity, $\mathrm{pH}$ and the yield point of WBM increase. MWCNT improves the shale integrity. PEG improves the shale recovery in the presence of MWCNT. Hence, MWCNT prevents the shale sample from any disintegration [21].

The present study investigates the effects of various kinds of Multi-Wall Carbon Nanotubes (MWCNT) on the performance of water base mud (WBM).

\section{Materials and Research Methodology \\ Materials}

a) Bentonite, potassium chloride, xanthan gum (viscosity agent) and PHPA were purchased from Kimyagaran Drilling 
Fluids, a leading trading company in the production and supply of the raw material for oil and gas drilling mud in Iran;

b) Caustic soda and polyethylene glycol 600 were purchased from Merck in Iran. Low viscosity grade polyanionic cellulose (fluid loss control additive) was purchased from Henzak Chemie Company in Iran;

c) Surface Modified Carbon Nanotube (Functionalize Carbon Nanotube [FCNT]) (MWCNT, diameter $=10-20 \mathrm{~nm}$, purity > $95 \%$, length of $10 \mu \mathrm{m}$ and Surface area: $250 \mathrm{~m}^{2} / \mathrm{g}$ );

d) Not Modified Carbon Nanotube (PCNT) (MWCNT, diameter $=10-20 \mathrm{~nm}$, purity $>95 \%$, length of $10 \mu \mathrm{m}$ and Surface area: $250 \mathrm{~m}^{2} / \mathrm{g}$ );

e) Greater Not Modified Carbon Nanotube (MCNT) (MWCNT, diameter $\geq 50 \mathrm{~nm}$, purity $>95 \%$, length of $20-30 \mu \mathrm{m}$ )

All kind of Multi-Wall Carbon Nanotubes (MWCNT) were produced in Research Institute of Petroleum Industry of Iran (RIPI) Surfactants that are used in this research are Tween 80 (T80) and Gum Arabic (GA) that are commonly used in the oil industry.
The local water analysis was done by ASTMD4691 method and the results are shown in (Table 1).

Table 1: Local water analysis.

\begin{tabular}{|c|c|c|c|}
\hline No. & Component & Amount & Unit \\
\hline 1 & $\mathrm{Na}$ & 1 & \\
\hline & & & $\mathrm{g} / \mathrm{L}$ \\
\hline 2 & $\mathrm{Mg}$ & 0.15 & \\
\hline 3 & $\mathrm{Ca}$ & 0.45 & \\
\hline 4 & $\mathrm{~K}$ & 9 & $\mathrm{mg} / \mathrm{L}$ \\
\hline
\end{tabular}

Table 2: X-Ray Differential (XRD) test result of the shale sample

\begin{tabular}{|c|c|c|}
\hline Sample & Test Method & Result \\
\hline D3536.75 & XRD & $\begin{array}{c}\text { 1-Quartz 2-Kaolinite } \\
\text { 3-Feldspar }\end{array}$ \\
\hline
\end{tabular}

X-Ray Differential (XRD) test result of the shale sample given in (Table 2).

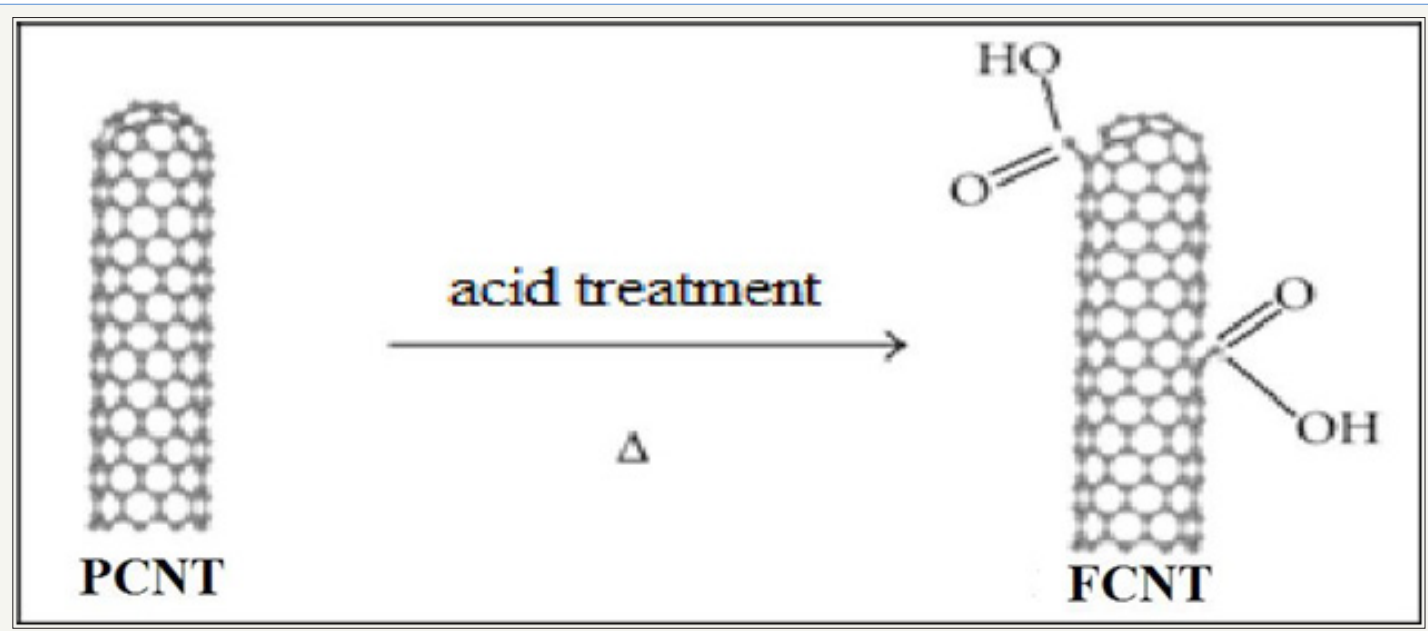

Figure 1: PCNT \& FCNT

MWCNT's do not disperse in water due to their hydrophobic characteristic. They can be hydrophilic by introducing hydrophilic functional groups to the surface of them by acid treatment as shown in (Figure 1).

\section{Experimental procedure}

\section{Samples preparation}

The entire tests were conducted in the Research Institute of Petroleum Industry (RIPI) of Iran.

First phase: Preparing the Nanofluid sample consisting of NPs, surfactant and water in their formulation. Nanofluids were prepared according to the formulation mentioned in (Table 3).
Table 3: Formulation of Nano-fluid

\begin{tabular}{|c|c|c|}
\hline Additive & Units & Amount \\
\hline Water & $\mathrm{ml}$ & 20 \\
\hline Surfactant & gr & 0.35 \\
\hline CNT & gr & 0.35 \\
\hline
\end{tabular}

In the first phase, surfactants were weighed and added to the beaker containing $20 \mathrm{cc}$ water and stirred by a magnetic stirrer for 5 minutes to prepare the target unique fluid. Afterward, the weighed MWCNT was added to the sample.

Table 4: Nano-fluid formulations

\begin{tabular}{|c|c|c|c|c|c|c|}
\hline NO. & Sample & CNT type & CNT (gr) & Local water (ml) & GA (gr) & T80 (gr) \\
\hline 1 & Nano DF/RAT & FCNT & 0.35 & 20 & - & 0.35 \\
\hline
\end{tabular}




\begin{tabular}{|c|c|c|c|c|c|c|}
\hline 2 & Nano DF/RAG & FCNT & 0.35 & 20 & 0.35 & - \\
\hline 3 & Nano DF/RAG.GEF & FCNT & 0.35 & 20 & 0.35 & - \\
\hline 4 & Nano DF/RPT & PCNT & 0.35 & 20 & 0.35 \\
\hline 5 & Nano DF/RPG & PCNT & 0.35 & 20 & - \\
\hline 6 & Nano DF/RPG.GEF & PCNT & 0.35 & 20 & 0.35 & - \\
\hline 7 & Nano DF/RMG.GEF & MCNT & 0.35 & 20 & 0.35 & - \\
\hline
\end{tabular}

Second phase: Ultrasonication

The sample was applied by ultrasound in the ultrasonic bath (P 120 H, Elmasonic Co., Germany) for 30 minutes under a frequency of $37 \mathrm{kHz}, 100 \mathrm{~W}$, and ambient temperature until the MWCNT distributed completely in the sample. In (Table 4), the formulation of Nanofluids with different surfactants is illustrated.

Table 5: Base mud formulations and mixing time duration \{Volume of water (320 or 340) + Volume of Nanofluid (20 ml) + Volume of additives $=350 \mathrm{ml}$ \}

\begin{tabular}{|c|c|c|c|c|c|c|c|c|c|c|}
\hline No. & Sample & $\begin{array}{c}\text { Local } \\
\text { water } \\
(\mathrm{ml})\end{array}$ & $\begin{array}{c}\text { Benton- } \\
\text { ite }(\mathrm{gr} / 350 \mathrm{ml})\end{array}$ & $\begin{array}{c}\text { KCl } \\
\text { (gr/350 } \\
\text { ml) }\end{array}$ & $\begin{array}{c}\mathrm{NaOH} \\
(\mathrm{gr} / 350 \mathrm{ml})\end{array}$ & $\begin{array}{c}\text { XG } \\
\text { (gr/350ml) }\end{array}$ & $\begin{array}{c}\text { PAC } \\
(\mathrm{gr} / 350 \mathrm{ml})\end{array}$ & $\begin{array}{c}\text { PHPA } \\
\text { (gr/350ml) }\end{array}$ & $\begin{array}{c}\text { PEG } \\
(\mathrm{gr} / 350 \mathrm{ml})\end{array}$ & rpm \\
\hline & & & MT:10 min & MT:3 min & MT:2 min & MT:5 min & MT:5 min & MT:10 min & MT:5 min & \\
\hline 1 & $\begin{array}{c}\text { Nano DF/ } \\
\text { RAT }\end{array}$ & 320 & 10 & 11.3 & 0.3 & 0.6 & 2 & 1 & - & 600 \\
\hline 2 & $\begin{array}{c}\text { Nano DF/ } \\
\text { RAG }\end{array}$ & 320 & 10 & 11.3 & 0.3 & 0.6 & 2 & 1 & - & 600 \\
\hline 3 & $\begin{array}{l}\text { Nano DF/ } \\
\text { RAG.GEF }\end{array}$ & 320 & 10 & 11.3 & 0.3 & 0.6 & 2 & 1 & 0.75 & 600 \\
\hline 4 & $\begin{array}{c}\text { Nano DF/ } \\
\text { RPT }\end{array}$ & 320 & 10 & 11.3 & 0.3 & 0.6 & 2 & 1 & - & 600 \\
\hline 5 & $\begin{array}{c}\text { Nano DF/ } \\
\text { RPG }\end{array}$ & 320 & 10 & 11.3 & 0.3 & 0.6 & 2 & 1 & - & 600 \\
\hline 6 & $\begin{array}{l}\text { Nano DF/ } \\
\text { RPG.GEF }\end{array}$ & 320 & 10 & 11.3 & 0.3 & 0.6 & 2 & 1 & 0.75 & 600 \\
\hline 7 & $\begin{array}{l}\text { Nano DF/ } \\
\text { RMG.GEF }\end{array}$ & 320 & 10 & 11.3 & 0.3 & 0.6 & 2 & 1 & 0.75 & 600 \\
\hline 8 & DF/BFBF & 340 & 10 & 11.3 & 0.3 & 0.6 & 2 & 1 & - & 600 \\
\hline 9 & DF/BFGEF & 340 & 10 & 11.3 & 0.3 & 0.6 & 2 & 1 & 0.75 & 600 \\
\hline
\end{tabular}

Third phase: Preparing base mud (sample without NPs). In (Table 5), the base mud with different formulations and mixing time (MT) durations are represented.

Firstly, the drilling fluid additives were weighed and mixed with water in Hamilton Beach stirrer with the same order of the additive phases and the mixing time mentioned in (Table 5). Finally, Nanofluids, produced in the first phase, were added and mixed for 10 minutes with the base mud sample. For preparing the base mud $340 \mathrm{ml}$ water was used and for Nanofluid $320 \mathrm{ml}$ water (local water) was used.

\section{Measuring rheological properties of WBM}

Rheological properties of samples measured by Fann viscometer model 35SA under six differences RPM $(600,300,200,100,6$ and $3 \mathrm{RPM}$ ) to reach plastic viscosity and yield point of the samples. $\mathrm{pH}$ of the samples measured by $\mathrm{pH}$ meter then mud density measured by mud balance. At last API (American Petroleum Institute) Filter press apparatus was used to measure the filtration properties of the samples.

\section{Shale recovery test}

The procedure of modified API RP 13-I was used in this study. Firstly, the shale grounding to a particle size less than $4 \mathrm{~mm}$ (mesh NO.5) and larger than $2 \mathrm{~mm}$ (mesh NO. 10) was applied. 20gm shale added to the fluid the samples. Samples allowed rolling in a roller oven for 8 hours at $121^{\circ} \mathrm{C}\left(250^{\circ} \mathrm{F}\right)$ for hot rolling. Then, the samples screened through mesh NO. 35 screen $(0.5 \mathrm{~mm})$ and then washed by using a saturated aqueous solution of sodium chloride and potassium chloride brine (15\%). The remaining shale on the sieve was washed to remove mud stuck to shale particles, before drying and reweighing. The high weight sample passed the screen (mesh 35) is an indication of the shale instability.

The shale recovery is calculated as:

Shale Recovery $=\frac{M I}{M F} \times 100$

MI = Initial mass of shale sample

$\mathrm{MF}=$ Final dry mass of shale sample 


\section{Shale Integrity test}

A shale tablet with a thickness diameter of 1 inch and $1 \mathrm{~cm}$ was put into the $350 \mathrm{cc}$ of WBM sample. Shale tablet was placed for 24 hours at the temperature of $93^{\circ} \mathrm{C}\left(200^{\circ} \mathrm{F}\right)$, and then shale tablet was put to dry in room temperature. Another shale tablet was put in the OBM sample and compared together physically after 2 tablets were dried.

\section{Result and Discussion}

\section{Rheological properties}

In (Table 6) the data obtained from different drilling muds is illustrated. Measuring Rheological properties after 16 hours is calling aging. The rheological and filtration properties of the muds are presented in (Table 7).

Table 6: Data obtained from the viscometer

\begin{tabular}{|c|c|c|c|c|c|c|c|}
\hline NO. & Sample & $\theta 600$ & $\boldsymbol{\theta} 300$ & Ө 200 & $\theta 100$ & $\theta 6$ & ө3 \\
\hline 1 & Nano DF/RAT & 55 & 44 & 38 & 30 & 14 & 12 \\
\hline 2 & Nano DF/RAG & 53 & 41 & 35 & 28 & 13 & 11 \\
\hline 3 & Nano DF/RAG (aging) & 52 & 40 & 34 & 27 & 13 & 11 \\
\hline 4 & Nano DF/RAG.GEF & 60 & 45 & 38 & 31 & 15 & 13 \\
\hline 5 & Nano DF/RAG.GEF (aging) & 58 & 45 & 38 & 31 & 15 & 13 \\
\hline 6 & Nano DF/RPT & 50 & 37 & 31 & 25 & 12 & 10 \\
\hline 7 & Nano DF/RPG & 53 & 41 & 35 & 28 & 13 & 11 \\
\hline 8 & Nano DF/RPG (aging) & 54 & 42 & 36 & 29 & 14 & 12 \\
\hline 9 & Nano DF/RPG.GEF & 49 & 38 & 33 & 26 & 13 & 11 \\
\hline 10 & Nano DF/RPG.GEF (aging) & 50 & 38 & 33 & 26 & 13 & 11 \\
\hline 11 & Nano DF/RMG.GEF & 52 & 40 & 36 & 29 & 16 & 13 \\
\hline 12 & DF/BFGEF & 64 & 48 & 42 & 34 & 21 & 15 \\
\hline 13 & DF/BFGEF (aging) & 64 & 49 & 43 & 35 & 17 & 14 \\
\hline 14 & $\mathrm{DF} / \mathrm{BFBF}$ & 51 & 39 & 34 & 27 & 14 & 12 \\
\hline 15 & DF/BFBF (aging) & 56 & 42 & 36 & 28 & 15 & 13 \\
\hline
\end{tabular}

Table 7: Rheological and filtration properties of the muds

\begin{tabular}{|c|c|c|c|c|c|c|}
\hline No. & Sample & PV (cp) & YP & pH & FL (cc) & CT $(\mathrm{mm})$ \\
\hline 1 & Nano DF/RAT & 11 & 33 & 9.8 & 8.4 & 0.6 \\
\hline 2 & Nano DF/RAG & 12 & 29 & 9.9 & 10 & 0.61 \\
\hline 3 & Nano DF/RAG (aging) & 12 & 28 & 11 & - & - \\
\hline 4 & Nano DF/RAG.GEF & 15 & 30 & 9.6 & - & - \\
\hline 5 & Nano DF/RAG.GEF (aging) & 13 & 32 & 10.9 & - & - \\
\hline 6 & Nano DF/RPT & 13 & 24 & 9.9 & 8.7 & 0.68 \\
\hline 7 & Nano DF/RPG & 12 & 29 & 9.8 & 8 & 0.83 \\
\hline 8 & Nano DF/RPG (aging) & 12 & 13 & 11.4 & - & - \\
\hline 9 & Nano DF/RPG.GEF & 11 & 27 & 9.8 & 6.4 & 0.91 \\
\hline 10 & Nano DF/RPG.GEF (aging) & 12 & 26 & 10.8 & - & - \\
\hline 11 & Nano DF/RMG.GEF & 12 & 28 & 12 & - & - \\
\hline 12 & DF/BFGEF & 16 & 32 & 11.3 & - & - \\
\hline 13 & DF/BFGEF (aging) & 15 & 34 & - & - & 13.2 \\
\hline 14 & $\mathrm{DF} / \mathrm{BFBF}$ & 12 & 27 & - & 7.1 & 0.72 \\
\hline 15 & DF/BFBF (aging) & 14 & 28 & 7.1 & 0.72 & 9.6 \\
\hline
\end{tabular}

$\mathrm{PV}=$ Plastic viscosity, $\mathrm{YP}=$ Yield point, $\mathrm{FL}=$ Filtrate loss and $\mathrm{CT}=$ Cake thickness 


\section{Effect of surfactant on Rheological Properties of WBM}

In this section, the effect of different surfactants will be compared on the viscosity of WBM. In (Figure 2), surfactants that were used in this study are shown.
The Viscosity rates of different samples at shear rates higher than $170 \mathrm{~s}^{-1}$ are almost identical. Therefore, we compare viscosity with shear rate below $200 \mathrm{~s}^{-1}$. Viscosity-shear rate trend of Nano DF/RPG and Nano DF/RPT is illustrated in (Figure 3).
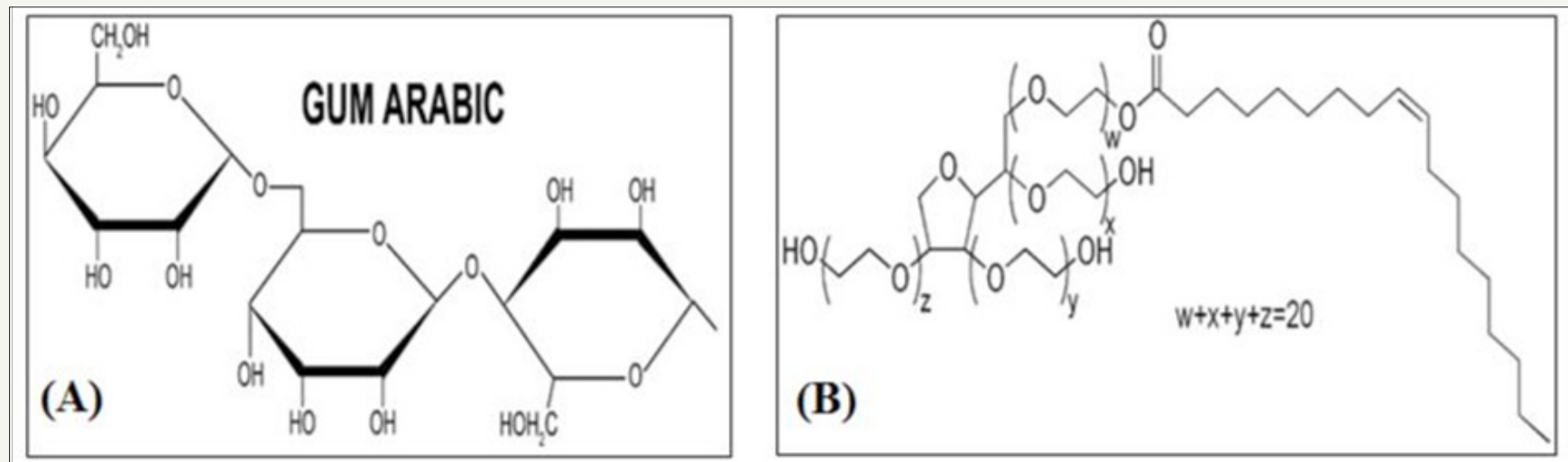

Figure 2: (A) GA surfactant (B) Tween 80 surfactant.

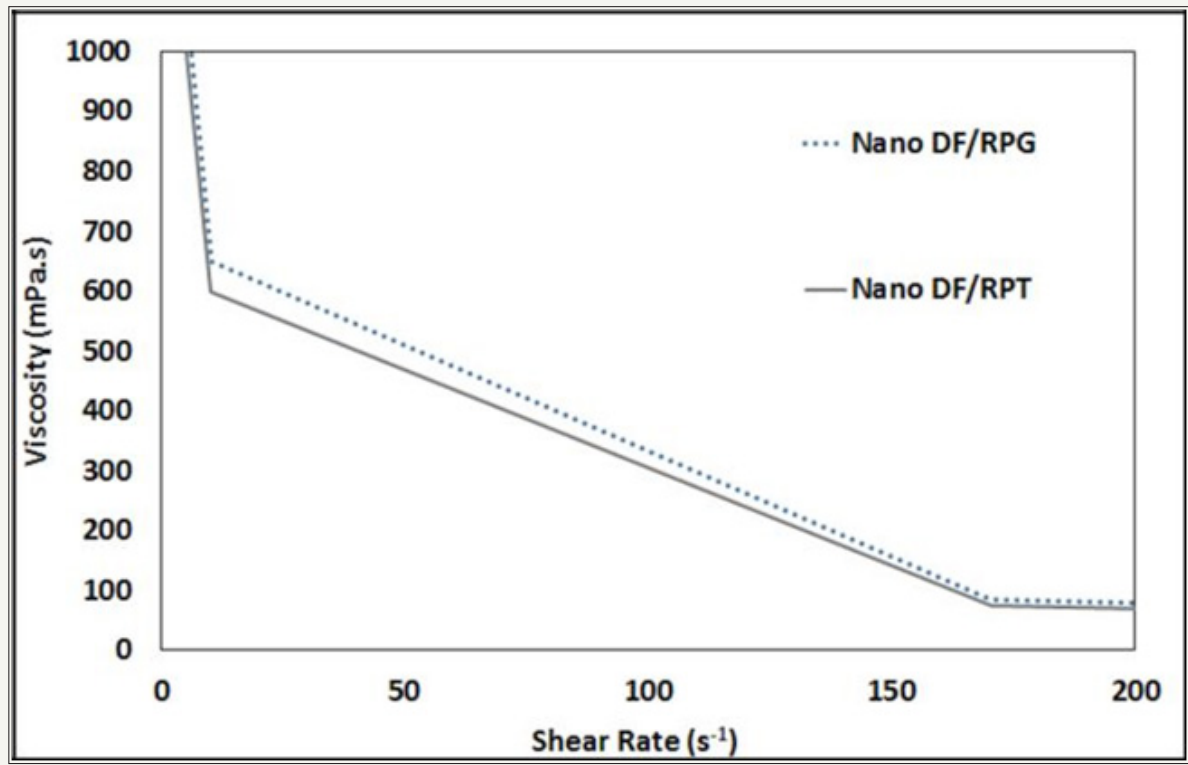

Figure 3: Viscosity-shear rate trend of Nano DF/RPG and Nano DF/RPT.

GA surfactant is used for preparing Nano DF/RPG and Nano DF/RAG. The T80 surfactant is used for preparing Nano DF/RPT and Nano DF/RAT. Other additives are the same in all samples. GA distributes MWCNT in the mud homogeneously, where it does not produce froth after stirring and produces stable WBM.

As shown in (Figure 2), GA and base mud are polar and PCNT is non-polar, thus not generating a good bond between PCNT, GA, and the base mud. T80 according to (Figure 2) has a polar (hydrophilic) head and a non polar (hydrophobic) head, but its polar head is mainly composed of ether groups. The ether polarity is low so creates a weak bond with the mud. That is the reason for lower viscosity and less improvement of rheological properties of the mud which are made of PCNT compare to another surfactant. GA is a relatively high molecular weight polymer, T80 is a low molecular weight polymer. Polymers have higher molecular weight and form a film to cover the pores of the filter paper, thereby reducing water loss. According to (Table 7) when PCNT is used as a nanoparticle in the drilling fluid, GA increases yield point and cake thickness and decrease water loss compares to T80.

Water loss and the filter cake of Nano DF/RAG and Nano DF/ RAT are shown in (Figure 4). In samples which are made by FCNT, the polar head of T80 absorbs FCNT and non-polar heads absorb to base mud. As (Figure 5) shows Nano DF/RAT has the higher viscosity than Nano DF/RAG. GA, base mud and FCNT as is shown in Figure 1 are polar so a good bond generated between the FCNT and the base mud which decreases friction and viscosity at a shear rate of $200 \mathrm{~s}^{-1}$. According to (Table 7) in the samples which are made by FCNT, GA increases fluid loss and plastic viscosity and decrease yield point compares to T80. T80 is producing stable foam during stirring. 


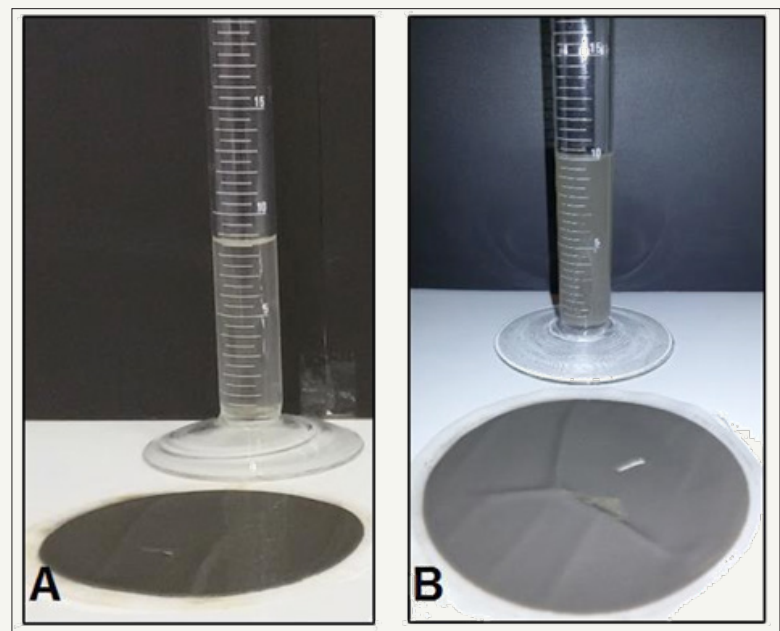

Figure 4: (A) Nano DF/RAT (B) Nano DF/RAG.

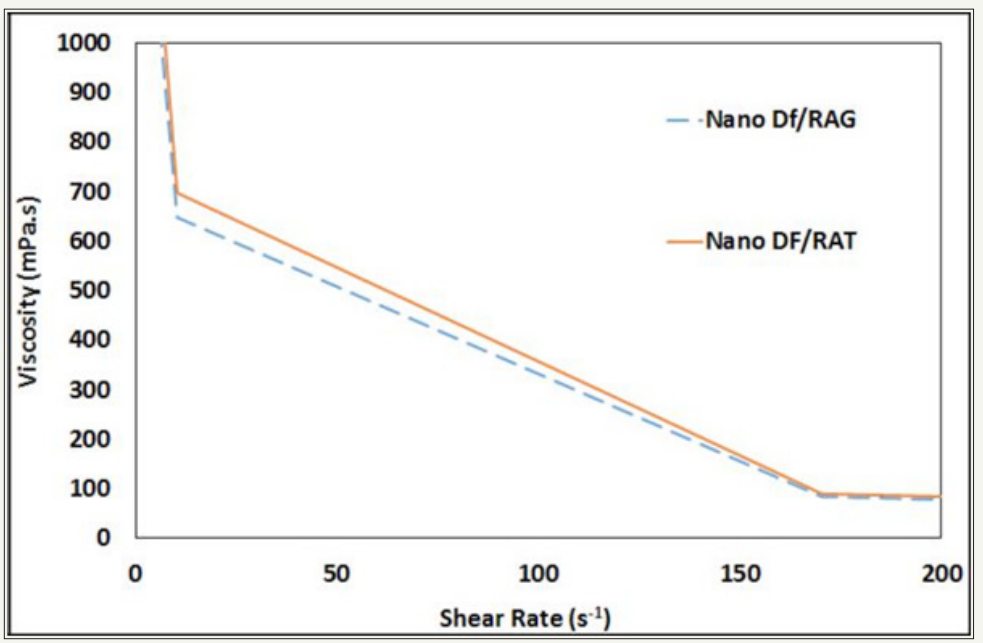

Figure 5: Viscosity-shear rate trend of Nano DF/RAG and Nano DF/RAT.

According to (Table 7) by comparing Nano DF/RPG and Nano DF/RAG samples, realize that GA with FMWCNT increases the amount of water loss, because Nano DF/RAG is most homogeneity in comparison with Nano DF/RPG. By comparing Nano DF/RPT and
Nano DF/RAT samples realize that T80 with FCNT increases yield point and decreases plastic viscosity in comparison with, T80 with PCNT.

\section{The effect of polyethylene glycol (PEG) on the rheological properties of WBM}

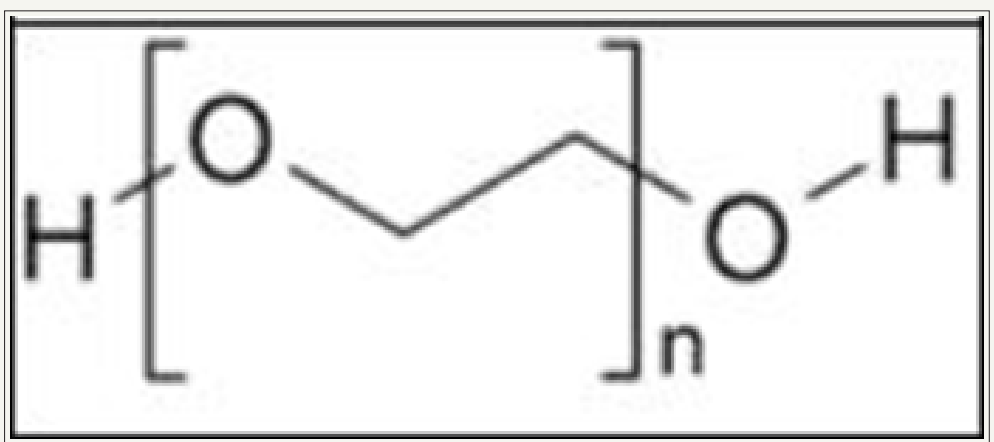

Figure 6: Polyethylene glycol.

In (Figure 6), Polyethylene glycol structure is shown. According to (Table 7) by comparing Nano DF/RPG.GEF and Nano DF/RPG, it is obvious that PCNT (non-polar) forms a non homogeneous sample; whereas a more non-homogenized sample is formed, when PEG (non-polar) is added. Thus, the viscosity and yield point of the sample containing PCNT and PEG is less than the sample without 
PEG. Adding PEG to the sample consisting PCNT, reduces viscosity, fluid loss and yield point of the sample and increases cake thickness of the mud.

According to (Table 7), by comparing two samples of Nano DF/RAG and Nano DF/RAG.GEF, it is observed that PEG increases the viscosity and yield point of the sample containing the FCNT. Because PEG has alcohol group $(\mathrm{OH})$ in its structure and forms a bond with the acid group $(\mathrm{COOH})$ in the FCNT. The other part of PEG is absorbed by the base mud and leading to increase viscosity and yield point of the sample.

According to (Table 7), by comparing two samples of DF/BFGEF and DF/BFBF, it is observed that PEG increases viscosity and yield point of the base mud.

\section{Effect of Nanoparticles on Rheological Properties of WBM}

Nano-carbon particles are added to the base mud to determine the effects of MWCNT on the performance of WBM. According to (Table 7): By adding FCNT to the DF/BFGEF sample, it leads to decrease plastic viscosity and yield point of the Nano DF/RAG. GEF sample. By comparing DF/BFGEF and Nano DF/RAG, it is observed that by using PEG instead of FCNT the plastic viscosity and the yield point will be reduced. By comparing Nano DF/RAG and Nano DF/ RPG samples, it is observed that FCNT increases the amount of water loss compared with the PCNT, because FCNT is polar and generates a good bond with mud and makes the sample more homogeneous. By comparing Nano DF/RAG and Nano DF/RAG.GEF, it can be understood that PEG increases PV and YP of the sample. The reason is that PEG has an alcoholic group in its structure that generates good bond with FCNT and another head is absorbing mud.

\section{Comparing Nano mud in the presence of PEG}

The rheological properties of Nano mud and base mud, in the presence of PEG are shown in (Table 7).

According to (Figure 7), by comparing DF/BFGEF and Nano DF/RAG.GEF, it is observed that FCNT reduces plastic viscosity and YP of the sample. By comparing of Nano DF/RMG.GEF, Nano DF/ RAG.GEF and Nano DF/RPG.GEF samples, it is concluded that FCNT in the presence of PEG increases the plastic viscosity and yield point of the sample in comparison with PCNT and MCNT. PEG due to its $\mathrm{OH}$ group generates a good bond with FCNT, so viscosity of Nano DF/RPG.GEF is lower than Nano DF/RAG.GEF. The diameter and length of MCNT used in Nano DF/RMG.GEF is more than PCNT used in Nano DF/RPG.GEF. Due to higher modulus and strength of larger CNT compare to smaller one plastic viscosity and yield point of Nano DF/RMG.GEF is more than Nano DF/RPG.GEF.

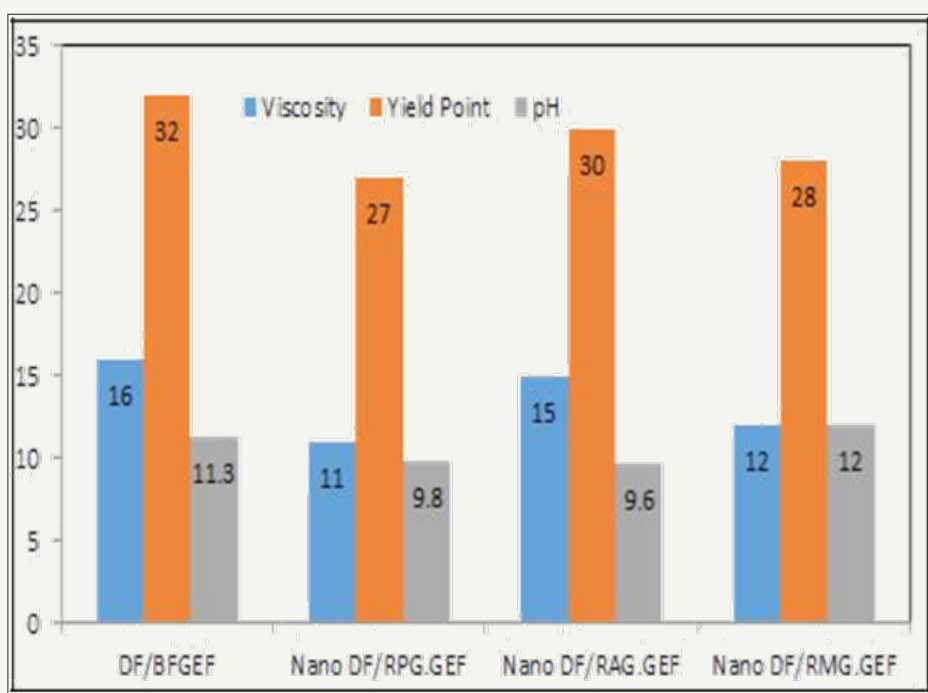

Figure 7: Rheological properties of Nano mud and base mud in the presence of PEG.

According to (Table 7) by comparing Nano DF/RPG and Nano DF/RAG, it is clear that in the absence of PEG, PCNT decreases the water loss in comparison with FCNT. In the presence of PEG, FCNT increases plastic viscosity and yield point of the sample in comparison with PCNT.

Nano DF/RAG.GEF and Nano DF/RAG have the same formulation, but Nano DF/RAG.GEF has PEG. As it is obvious in (Table 7), PEG increases viscosity and yield point of the sample.

\section{Role of carbon nanotubes on aging of WBM in the presence of PEG}

The Rheological properties of samples after 16 hours aging is shown in (Figure 8). In this part, the role of aging on the rheological properties of WBM in the presence of PEG is examined. For this purpose, the rheological properties were measured immediately after preparing the sample and once after 16 hours. It is very important that the rheological properties of WBM sample does not alter over time and be stable. If mud properties are affected excessively over time, it causes huge losses in the drilling industries. For this purpose, the drilling fluid should have maximum stability during drilling operations.

As shown in (Figure 8) and (Figure 7) the properties of the samples having MWCNT did not change excessively after 16 hours aging and their plastic viscosity and yield point are almost stable. The reason is that MWCNT can maintain the polymers against degradation as mentioned by Halali [22]. 


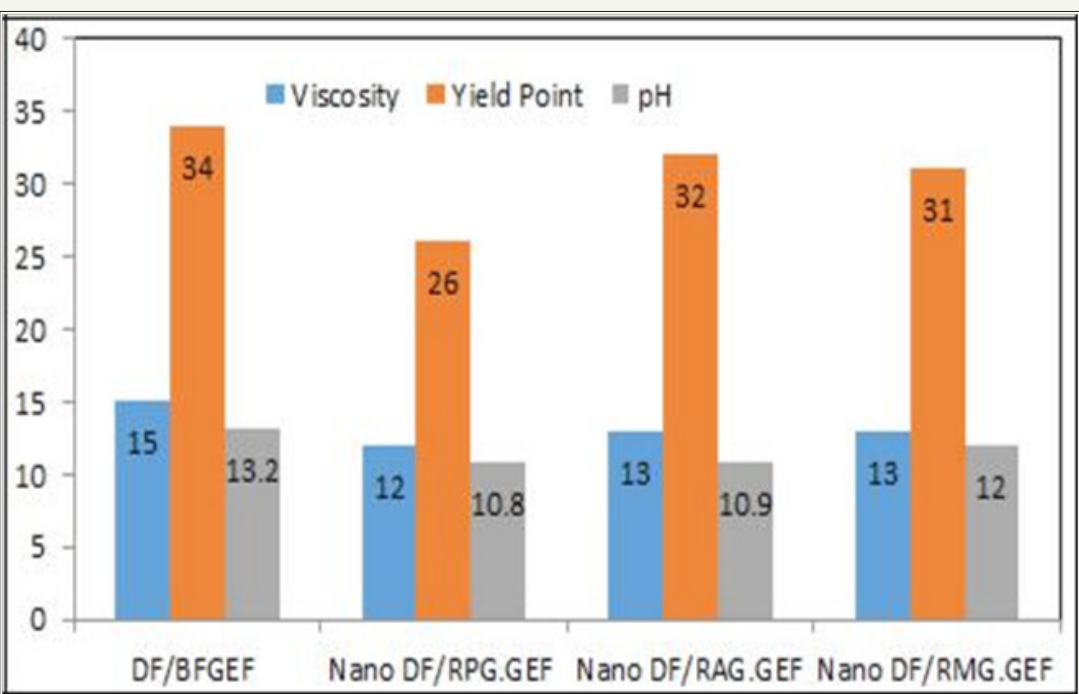

Figure 8: Rheological properties after 16 hours aging.

\section{Shale's recovery test results}

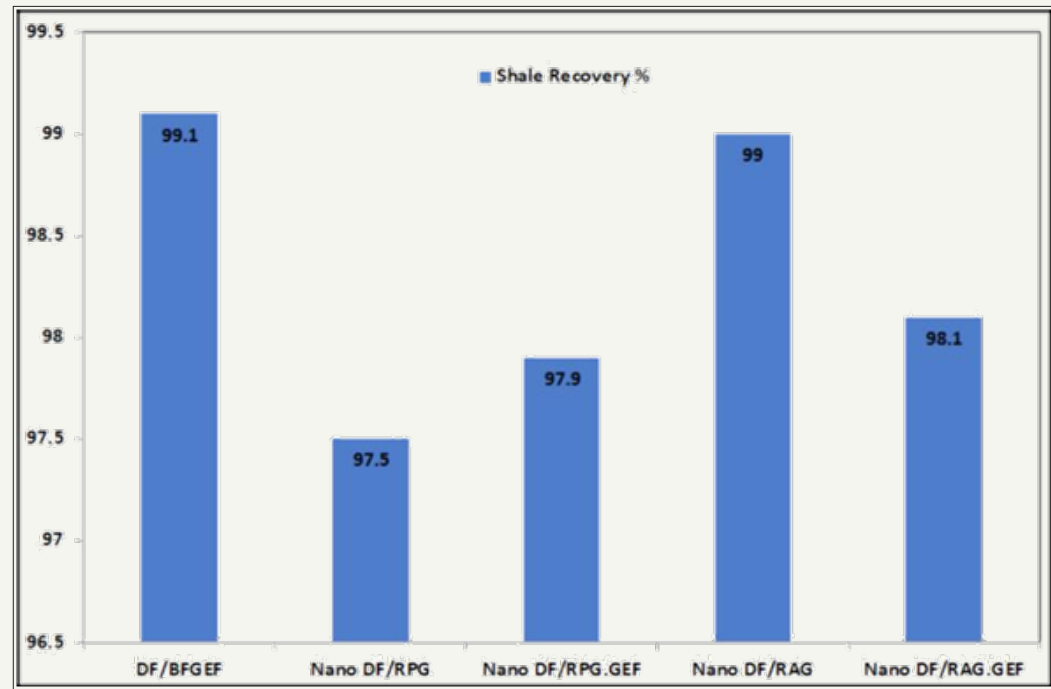

Figure 9: Shale recovery of drilling muds.

Table 8: Data obtained from shale recovery test

\begin{tabular}{|c|c|c|c|c|}
\hline No. & Sample & Initial Mass of Shale Sample & Final Dry Mass of Shale Sample & Shale Recovery \% \\
\hline 1 & Nano DF/RPG & 20 & 19.5 & 97.5 \\
\hline 2 & DF/BFGEF & 20 & 19.82 & 99.1 \\
\hline 3 & Nano DF/RPG.GEF & 20 & 19.58 & 97.9 \\
\hline 4 & Nano DF/RAG & 20 & 19.8 & 99 \\
\hline 5 & Nano DF/RAG.GEF & 20 & 19.62 & 98.1 \\
\hline
\end{tabular}

In (Figure 9), the quantities of the shale recovery of the samples are shown. The data obtained from the shale recovery test are represented in (Table 8).

As shown in (Figure 9), by comparing Nano DF/RPG and DF/ BFGEF, it is determined the PCNT in comparison with PEG reduces the shale recovery. When PEG is absorbed on the surface of the shale, it maintains the shale particles together and improves the shale recovery of the samples. By comparing samples of Nano DF/
RPG.GEF and Nano DF/RAG.GEF with DF/BFGEF, it is determined that adding of CNT to base mud reduces the shale recovery. The reason is that some amount of polyethylene glycol is absorbed by carbon nanotubes. By comparing samples of Nano DF/RPG and Nano DF/RPG.GEF, it is determined that PEG can improve the shale recovery in the presence of carbon nanotubes, because PEG is absorbed on shale's surface and makes it stable. By comparing Nano DF/RAG and Nano DF/RPG, it is realized that FCNT, due to 
its polar group absorbs shale and keep shale particles together and increases the shale recovery rates. In another hand the shale has surface with the negative charge, so the acidic group of FCNT absorbs it and increases shale recovery. By comparing Nano DF/ RPG.GEF and Nano DF/RAG.GEF, it is determined that FCNT in the presence of PEG is more effective than PCNT in the shale recovery. By comparing Nano DF/RPG and Nano DF/RPG.GEF, it is realized that PEG improves shale recovery in the presence of PCNT, Because PEG is absorbed on the shale surface. By comparing Nano DF/ RAG and Nano DF/RAG.GEF, it is determined that PEG reduces the recycling of shale in the presence of FCNT. FCNT and PEG absorb each other, due to their $\mathrm{OH}$ and $\mathrm{COOH}$ groups, and cover shale surface less.

\section{Conclusion}

According to the tests in the following, the experimental results have been represented. In the presence of Not Modified Carbon Nanotube (PCNT), by utilizing GA as the surfactant decreases the water loss and increases the cake thickness of the Mud (WBM). In the presence of Surface Modified Carbon Nanotube (FCNT), by using T80 as the surfactant increases yield point and decreases plastic viscosity. By adding Multi-Wall Carbon Nanotubes (MWCNT) and PEG alone or together have different effects on the rheological properties of WBM. The addition of MWCNT alone almost improves the rheological properties of the WBM, while the addition of PEG alone reduces the rheological properties of the base mud. Furthermore, the addition of PEG to the sample consisting of MWCNT reduces the viscosity of the mud. Carbon nanotubes reduce the recovery of shale in comparison with PEG. PEG and MWCNT together reduce the viscosity of the mud. FCNT increases the quantity of plastic viscosity, yield point and water loss of the sample in comparison with PCNT. In the presence of PEG, FCNT increases the plastic viscosity and yield point of the sample more than PCNT and Greater Not Modified Carbon Nanotube (MCNT). MCNT increases viscosity and yield point of the sample due to its greater diameter and length than PCNT. By increasing the size (diameter and length) of MWCNT more viscosity, $\mathrm{pH}$ and yield point of the WBM is achieved. Without PEG in the presence of T80 as a surfactant, PCNT in comparison with FCNT increases the yield point of the mud. FCNT has more efficiency than PCNT in the shale recovery. PEG improves the shale recovery in the presence of PCNT. PEG diminishes the shale recovery in the presence of FCNT. The presence of Multi-Wall Carbon Nanotubes increases the efficiency of polymers and improves the rheological properties and performance of the water base mud.

\section{Acknowledgment}

The author would like to thank Mr. Mohammad Tavana and Mr Kazemzadeh for supporting this article.

\section{References}

1. Steiger, Ronald P, Peter K (1992) Leung Quantitative determination of the Mechanical Properties of Shales. SPE drilling engineering 7(3): 181185.

2. Van Oort E, Hale AH, Mody FK (1996) Transport in shales and the design of improved water-based shale drilling fluids. SPEDC2 p. 25-28.
3. Amanullah Md, Ziad Al-Abdullatif (2014) Drilling, drill-in and completion fluids containing nanoparticles for use in oil and gas field applications and methods related thereto.

4. Lomba R, Sharma MM, Chenevert M (1996) Electrochemical Aspects of Wellbore Stability: Ionic Transport through Confined Shales. International Journal of Rock Mechanics and Mining Sciences and Geomechanics Abstracts.

5. Joel OF, Durueke UJ, Nwokoye CU (2012) Effect of KCL on Rheological Properties of Shale Contaminated Water-Based MUD (WBM). Global Journals 12(1).

6. Bloys Ben (1994) Designing and managing drilling fluid. Oilfield Review $6(2)$.

7. Mody, Fersheed K, Uday AT, Chee PT, Calum JD, Bailin Wu (2002) Development of Novel Membrane Efficient Water-Based Drilling Fluids through Fundamental Understanding of Osmotic Membrane Generation in Shales. SPE Annual Technical Conference and Exhibition. Society of Petroleum Engineers.

8. Van OE (2017) On the Physical and Chemical Stability of Shales. Journal of Petroleum Science and Engineering 38(3-4): 213-215.

9. Zhixin Yu, Irfran Y, Sui D, Agista MN (2017) The Potential of Nanotechnology in Petroleum Industry with Focus on Drilling Fluids. Pet Petro Chem Eng J 1(1).

10. Sensoy, Taner, Martin E, Chenevert, Mukul MS (2009) Minimizing water invasion in shales using nanoparticles. SPE Annual Technical Conference and Exhibition. Society of Petroleum Engineers.

11. Chenevert, Martin E, Mukul MS (2014) Maintaining shale stability by pore plugging

12. Fazelabdolabadi, Babak, Abbas AK, Mostafa Sedaghatzadeh (2015) Thermal and rheological properties improvement of drilling fluids using functionalized carbon nanotubes. Applied Nanoscience 5(6): 651-659.

13. Amanullah Md, Mohammed AlArfaj, Ziad Abdullrahman (2011) Preliminary Test Results Of Nano-Based Drilling Fluids For Oil And Gas Field Application. SPE/IADC Drilling Conference and Exhibition. Society of Petroleum Engineers.

14. Ji L, Guo Q, Friedheim, Zhang R, Chenevert M, Sharma M (2012) Drilling Unconventional Shales with Innovative Water Based Mud - Part 1: Evaluation of Nanoparticles as Physical Shale Inhibitor. AADE Fluids Technical Conference, Houston.

15. Sedaghatzadeh, Mostafa, and Abbasali Khodadadi. "An improvement in thermal and rheological properties of water-based drilling fluids using multiwall carbon nanotube (MWCNT)." Iranian Journal of Oil \& Gas Science and Technology 1.1, 2012.

16. Passade Boupat, Nicolas, Cathy Rey, Mathieu Naegel (2013) Drilling Fluid Containing Carbon Nanotubes.

17. Young, Steve, James Friedheim, Arvind D. Patel, James Tour, and Dmitry Kosynkin. "Graphene-based material for shale stabilization and method of use." U.S. Patent Application 13/877,852, filed October 6, 2013.

18. Amanullah Md, Ziad Al-Abdullatif (2014) Drilling, Drill-In and Completion Fluids Containing Nanoparticles for Use in Oil and Gas Field Applications and Methods Related Thereto.

19. Quintero, Lirio, Antonio EC, David EC (2014) Nanofluids and methods of use for drilling and completion fluids.

20. Amanullah Md, Ashraf M Al-Tahini (2009) Nano-Technology-Its Significance in Smart Fluid Development for Oil and Gas Field Application. SPE Saudi Arabia Section Technical Symposium. Society of Petroleum Engineers.

21. Koorosh T, Javad H, Mohammad Soleymani, Alimorad R, Mahdi Nazarisaram (2018) Analyzing Effects of Multi-Wall Carbon Nanotubes (MWCNT) \& Polyethylene Glycol (PEG) on Performance of Water Base Mud (WBM) in Shale Formation. The Open Petroleum Engineering Journal 11: 29-47. 
22. Halali, Cyrus Ghotbi, Kourosh Tahmasbi, Hossein Ghazanfari (2016) The Role of Carbon Nanotubes in Improving Thermal Stability of Polymeric
Fluids: Experimental and Modeling. Industrial \& Engineering Chemistry Research 55(27): 7514-7534. (c) (P) $\begin{aligned} & \text { Creative Commons Attribution } 4.0 \\ & \text { International License }\end{aligned}$

For possible submissions Click Here Submit Article

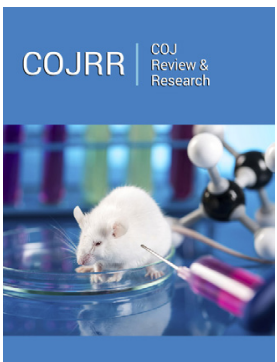

\section{COJ Reviews \& Research}

\section{Benefits of Publishing with us}

- High-level peer review and editorial services

- Freely accessible online immediately upon publication

- Authors retain the copyright to their work

- Licensing it under a Creative Commons license

- Visibility through different online platforms 